\title{
Comparison of Spiritual Experiences and Distress Tolerance between Women with Type 2 Diabetes and Healthy Counterparts: A Cross-Sectional Study
}

\author{
Maryam Amerifar ${ }^{1}$, Anahita Khodabakhshi Koulayi², Akram Sanagoo*3
}

1. Department of Counseling, Islamic Azad University, Electronic Branch, Tehran, Iran

2. Department of Psychology and Education, Faculty of Humanities, Khatam University, Tehran, Iran

3. Nursing Research Center, Golestan University of Medical Sciences, Gorgan, Iran

\begin{abstract}
Background and objectives: Diabetes is one of the main causes of morbidity and mortality worldwide. Spiritual experiences and religious belief can reduce tension and improve physical and mental health in diabetic patients. The purpose of this study was to compare spiritual experiences and distress tolerance between women with type 2 diabetes and healthy counterparts in Tehran, Iran.

Methods: This descriptive and cross-sectional study was carried out on 100 women with type 2 diabetes who were selected from the Ferdowsi Diabetes Clinic (Tehran, Iran) and 100 non-diabetic counterparts. The participants responded to the Daily Spiritual Experience Scale and the Distress Tolerance Scale. Data were analyzed with SPSS 19 using independent t-test.

Results: The mean score of daily spiritual experiences in women with diabetes $(61.35 \pm 13.54)$ was significantly higher than that in the healthy counterparts $(47.47 \pm 12.57)(\mathrm{P}<0.01)$. Also, the mean score of distress tolerance was significantly higher in women with type 2 diabetes $(44.69 \pm 12.58)$ than in the controls $(39.85 \pm 9.65)(\mathrm{P}<0.01)$.

Conclusion: The results of the study showed that spiritual experiences and distress tolerance can be effective in improving the quality of life of people with type 2 diabetes.

KEYWORDS: Distress tolerance; Diabetes; Spirituality
\end{abstract}

\section{Received: 2019/04/04 $\quad$ Revised: 2019/04/18 Published:2019/05/01}

*Correspondence: Akram Sanagoo

Address: Nursing Research Center, Golestan University of Medical Sciences, Gorgan, Iran

Telephone: +98-9112703978 Email: sanagoo@goums.ac.ir 


\section{INTRODUCTION}

Diabetes is a chronic disease that influences individual, social and psychosocial functioning (1). It is one of the major causes of morbidity, mortality and increased health care costs worldwide (2). There are currently over 180 million diabetics in the world, and it is estimated that this number will double by the year 2030 (3). The disease can also lead to cardiovascular disease, blindness, renal failure, lower limb amputation, pregnancy complications and flue-related death $(4,5)$. Factors such as stress, socioeconomic problems, smoking, alcohol consumption, engaging in hazardous occupations, unhealthy diet, insufficient physical activity and obesity can affect the quality of life of patient with type 2 diabetes (6). The psychosocial complications of diabetes includes pain, anxiety, marital and familial problems, occupational problems, nutritional problems and inability to make decisions (7-10).

According to Melkus (2008), spirituality should be emphasized for a better glycemic control in patients with diabetes (11). In recent decades, many have recognized beliefs and spiritual experiences as important factors of physical health, well-being and treatment process (12). Research has shown that spiritual experiences not only affect the mood, mental health and physical well-being, but also improve the immune and endocrine systems (13). Studies have shown that spiritual experiences improve the quality of life, promote mental health and reduce stress in women with diabetes (14). Although religious beliefs and spiritual experiences may not cure a patient, they can help the patient cope with the disease, associated problems and risk of death (15).

Another psychological factor that can be related to diabetes control is distress tolerance. Stress and distress are the body's reaction to adverse environmental conditions. Nevertheless, low amount of stress could be beneficial and makes life more attractive. Tensions provide people with the opportunity to make effort and deal with risks in their lives. Excessive tension can cause critical situations that could endanger individual and social life (16). Individuals with low distress tolerance engage in an erroneous attempt to cope with negative emotions, which leads to behavioral disorder (17-19).

Considering the above-mentioned issues and the increasing prevalence of diabetes, the present study aims to determine and compare spiritual experiences and distress tolerance in individuals with and without type 2 diabetes.

\section{MATERIAL AND METHODS}

This descriptive-analytical study was carried out on 100 women with type 2 diabetes (aged 35-60 years) who were referred to the Ferdowsi Diabetes Clinic in Tehran (Iran) during April and May 2018. Aged-matched healthy control individuals were selected from volunteers who participated in morning exercise at the Laleh Park in Tehran, Iran.

Inclusion criteria included having type 2 diabetes for at least five years and enough education for understanding and responding to questionnaires. Exclusion criteria included having a mental disorder, lack of cooperation with the researcher and participation in psychological interventions for improving mental status. Written consent was obtained from all participants. Data were collected using the following questionnaires: the Daily Spiritual Experience Scale (DSES) and the Distress Tolerance Scale (DTS).

DSES was first created by Underwood and Teresi (2002) as a multidimensional tool of spirituality in order to effectively examine diverse areas of religion and spirituality in health studies $(20,21)$. The scale has 16 items in which higher scores represent less spiritual experience. However, we reversed this rule for easier interpretation of results (i.e. higher scores indicate more spiritual experiences). In a review by Tonigan et al. (2002), the internal consistency (Cronbach's alpha) of the scale was found to be 0.94 and 0.95 (21). Taghavi and Amiri (2010) reported a Cronbach's alpha of 0.88 in the test and 0.92 in the retest (23).

DTS is an epidemiological self-evaluation index of emotional distress tolerance that was developed by Simons and Gaher in 2005. The 
scale has 15 items and Cronbach's alpha of 0.82 (17) and $0.86(23)$.

The collected data were analyzed with SPSS 19 using independent t-test.

\section{RESULTS}

The demographic characteristics of the participants are shown in table 1.

Table 1. Demographic characteristics of all subjects

\begin{tabular}{|c|c|c|c|}
\hline \multicolumn{2}{|c|}{ Variable } & Frequency & Percent \\
\hline \multirow{2}{*}{ Age } & $30-50$ years & 65 & 32.5 \\
\cline { 2 - 4 } & $50-60$ years & 135 & 67.5 \\
\hline \multirow{2}{*}{ Marital status } & Married & 164 & 82 \\
\cline { 2 - 4 } & Single & 36 & 18 \\
\hline \multirow{2}{*}{ Education level } & $\begin{array}{c}\text { High school } \\
\text { diploma }\end{array}$ & 62 & 31 \\
\cline { 2 - 4 } & University degree & 138 & 69 \\
\hline \multirow{2}{*}{ Severity of hyperglycemia } & Mild & 82 & 41 \\
\cline { 2 - 4 } & Severe & 118 & 59 \\
\hline
\end{tabular}

As shown in table 2, results of the t-test showed a significant difference between the mean score of spiritual experiences of diabetic and non-diabetic women $(\mathrm{P}=0.001)$. Moreover, the mean score of distress tolerance in women with type 2 diabetes (44.69) was significantly higher than that in non-diabetic women (39.85).

Table 2. Comparison of the mean scores for spiritual experiences and distress tolerance in women with and without type 2 diabetes

\begin{tabular}{|c|c|c|c|c|c|c|}
\hline Variable & Group & Mean & $\begin{array}{c}\text { Standard } \\
\text { deviation }\end{array}$ & T & df & $\begin{array}{c}\text { P- } \\
\text { value }\end{array}$ \\
\hline $\begin{array}{c}\text { Spiritual } \\
\text { experiences }\end{array}$ & Diabetics & 61.35 & 13.548 & 7.911 & 198 & 0.001 \\
\cline { 2 - 7 } & Control & 47.47 & 12.578 & 7.911 & 198 & 0.001 \\
\hline $\begin{array}{c}\text { Distress } \\
\text { tolerance }\end{array}$ & Diabetics & 44.69 & 12.588 & 3.051 & 198 & 0.003 \\
\cline { 2 - 7 } & Control & 39.85 & 9.659 & 3.051 & 198 & 0.003 \\
\hline
\end{tabular}

\section{DISCUSSION}

The results showed that the level of spiritual experiences in women with type 2 diabetes is higher than in non-diabetic women. This finding is consistent with findings of Shahdadi et al. (2015) that indicated a relationship between spiritual health and glycemic control in diabetics (25). Another study found a positive relationship between spirituality and disease tolerance (19). Another study claimed that frequent pray is associated with improved mental health and reduced depression and anxiety (26). Spirituality and spiritual practice can increase motivation and improve self-care and glycemic control in diabetic patients (27). Religious and spiritual resources not only
Help patients overcome difficulties, but also improve their quality of life (28). Spiritual people are happier, live longer and generally have a better quality of life (26).

Similar to our results, another study found that level of distress tolerance is higher in women with type 2 diabetes. Elstad (2008) revealed that increased environmental, familial and personal distress increases glucose levels (29). Kumari et al. (2004) found that high occupational distress, poor social support and long working hours may be involved in the increasing incidence of diabetes (30). Glycemic control has a significant correlation with diet in diabetic 
patients with sustainable mental and social resources, such as education, marriage and distress-coping strategies $(30,31)$. Patients with lower level of distress have favorable metabolic control, while those who experience higher level of distress have poor metabolic control (32).

Among limitations of the present study, we can point out the intrinsic limitations of crosssectional studies, limited diversity of subjects (all subjects were women and selected from one city) and the fact that the control subjects were exercising regularly, which could have influenced psychological factors and distress tolerance.

\section{CONCLUSION}

Spiritual experiences and distress tolerance are psychological components that can help diabetic women adapt to their illness and control blood glucose levels. Therefore, it is recommended to health professionals to consider these two components when dealing with diabetic patients. In addition to drug therapy, therapeutic centers for diabetics can also exploit empowerment of psychological skills, such as coping with stress and problem solving.

\section{ACKNOWLEDGEMENTS}

The authors would like to thank all participants in the study for their cooperation. The results have been derived from a thesis approved by the Islamic Azad University, Electronic Branch, Iran.

\section{DECLARATIONS}

\section{Funding}

Not applicable.

\section{Ethics approvals and consent to participate}

The study has been approved (code: 950237060) by the ethics committee of the Islamic Azad University, Electronic Branch, Iran.

\section{Conflict of interest}

The authors declare that there is no conflict of interest regarding publication of this article.

\section{REFERENCES}

1. Amiri Z, Yazdanbakhsh KK. Comparison of Coping Styles and Mental Health in Patients with Type II Diabetes and Non-diabetic Individuals. Journal of Diabetes Nursing. 2014; 2(3): 20-8. [Persian]

2. Hajizad R, Abdollahzadeh H, Gholami M. The Impact of Training Spiritual/religious Coping Skills on Level of Anxiety and Stress Coping Strategies of Patients With Type II Diabetes to Provide Nursing and Caring Strategies . Journal of Diabetes Nursing. 2016; 4 (4): 72-83. [Persian]

3. James E, Diane G, Stoebner M, Glenn, V. Health Related Quality Of Life In Older Mexican Americans With Diabetes. Health And Quality Of Life Out Comes. 2007; 5(39): 1-7. [DOI:10.1186/1477-7525-5-39]

4. Akbarnataj K, Hassanzadeh R, Dousti Y, Fakhri M, Shirafkan A. The Effects of Some Psychological Comorbidities and Diabetes: A Review Article. Journal of Diabetes Nursing. 2014; 2(3): 69-83. [Persian]

5. WHO Media Centre. Diabetes [Online]. 2012. Available from: http://www. Who.Int diabetes/10 facts about diabetes.

6. Bianco A, Pomara F, Thomas E, Paoli A, Battaglia G, Petrucci M, et al. Type 2 Diabetes Family Histories, Body Composition and Fasting Glucose Levels: A Cross-Section Analysis in Healthy Sedentary Male and Female. Iran J Public Health. 2013; 42(7): 681-90.

7. Brunner LS, Smeltzer SCOC, Bare BG, Hinkle JL, Cheever KH. Brunner \& Suddarth's textbook of medicalsurgical nursing. Wolters Kluwer Health/Lippincott Williams \& Wilkins; 2010.

8. Alonso-Moran E, Satylganova A , Orueta JF , Nuno-Solinis R. Prevalence of depression in adults with type 2 diabetes in the Basque Country: relationship with glycaemic control and health care costs. BMC Public Health. 2014; 14(769): 18 . [DOI:10.1186/1471-2458-14-769]

9. Paasche-Orlow MK, Parker RM,Gazmararian JA, Nielsen-Bohlman LT, Rudd RR. The prevalence of Limited health literacy. J Gen Intern Med. 2005; 20(2): 175-84 . [DOI:10.1111/j.15251497.2005.40245.x] 
10. Tol A, Pourreza A, Tavasoli E, Rahimi Foroshani A. Determination of knowledge and health literacy among women with type 2 diabetes in teaching hospitals of TUMS. Journal of Hospital .2010; 3(11): 45-52. [Persian]

11. Melkus G. Harrisons Principles of international medicine. 1th ed. New York, McGraw-Hill; 2008.

12. Lo C, Zimmermann C, Gagliese L, Li M, Rodin G. Sources of spiritual well-being in advanced cancer. BMJ supportive palliative care .2011;1(2):149-53. 2011-000005]

13. White ML, Peters R, Schim SM. Spirituality and spiritual self-care: expanding self-care deficit nursing theory. Nurs Sci Q .2011; 24(1):48-56. [DOI:10.1177/0894318410389059]

14. Khodabakhshi Koolaee A, Falsafinejad M, Navidian A. Evaluation of effectiveness of resilience training on psychological wellbeing of patients with type II diabetes. J Diabetes Nurs. 2016; 4(3): 30-40 . [Persian] [DOI:10.32598/jccnc.2.1.3]

15. Parsian N, Dunning T. Spirituality and coping in young adults with diabetes. Diabetes Res clinic Prac 2008; 79: SI- SI27. [DOI:10.1016/S01688227(08)70950-1]

16. Newlin K, Melkus GD, Tappen R, Chyun D. and Doenig HG. Relationships of religion and spirituality to glycemic controlin black women with Type 2 diabetes. Nurs Res. 2008; 57: 331339

[DOI:10.1097/01.NNR.0000313497.10154.66]

17. Simons J \& Gaher R. The Distress Tolerance Scale: Development and validation of a self-report measure. Motivation and Emotion.2005; 29(2): 83-102. [DOI:10.1007/s11031-005-7955-3]

18. O'Cleirigh C, Ironson G \& Smits J. Does distress tolerance moderate the impact of major life events on psychosocial variables and behaviors important in the management of HIV?. Behavior therapy.2007; 38(3): 314-323. [DOI:10.1016/j.beth.2006.11.001]
19. Zvolensky M, Bernstein A \& Vujanovic A. Distress tolerance: Theory, research, and clinical applications. Guilford Press; 2011.

20. Mitchell M, Riccardi C, Keough M, Timpano $\mathrm{K} \&$ Schmidt N. Understanding the associations among anxiety sensitivity, distress tolerance, and discomfort intolerance: A comparison of three models. Journal of Anxiety Disorders.2013; 27(1): 147-154. [DOI:10.1016/j.janxdis.2012.12.003]

21. McHorney, C.A.,Ware, J. E., Rachel, L.,\& Sherburne, C.D. The MOS 36-item short-form health survey (SF-36): tests of data quality, scaling assumptions, and reliability across diverse patient groups. Medical care.1994; 32,40-66. [DOI:10.1097/00005650-199401000-00004]

22. Tonigan, J.,Walter, S.and Underwood, L. Test-retest study of the brief measure of religiousness and spirituality among treatment seeking substance users. Manuscript submitted for publication; 2002.

23. Taghavi SHR., Amiri H. Psychoanalysis Characteristic Investigation Daily Spiritual Experience Scale (DSES). Bi-quarterly Journal of Islamic Education, 2010;5(10): 151-167. (Full text in Persian)

24. Andami Khoshk A, Golzar M, Esmaeili Nasab M. Role of Nine Strategies of Cognitive Emotion Regulation in the Prediction of Resilience. Journal of Thought \& Behavior in Clinical Psychology. 2013;7(27):61-70.[Persian]

25. Shahdadi H, Dindar M, Mohammadpour Hadki R, Sadegh S, Masinaienejhad N. The relationship between spiritual health and blood glucose control in patients with type 2 diabetes. Quarterly Journal of Nursing Diabetes. Zabol University of Nursing and Midwifery. 2015;3(2): 43-54. [Persian]

26. Polzer R. and Miles MS. Spirituality and selfmanagement of Diabetes in African Americans. J Holist Nurs .2005; 23: 230-250. [DOI:10.1177/0898010105276179]

27. Williams D \& Sternthal M. Spirituality, religion and health: evidence and research directions. Medical Journal of Australia.2007; 186 (10): S47-S50. 
28. Yiu A, Christensen K, Arlt JM, Chen EY. Distress tolerance across self-report, behavioral and psychophysiological domains in women with eating disorders, and healthy controls. Journal of behavior therapy and experimental psychiatry. 2018;1;61:24-31.

[DOI:10.1016/j.jbtep.2018.05.006]

29. Elstad E. Living with Ma'I Suka: individual, familial, cultural, and environmental stress among patients with type 2 diabetes mellitus and their caregivers in American Samoa. J Prev Chronic Dis. 2008.5(3);A79.

30. Kumari M, Head J, Marmot M. Prospective study of social and other risk factors for incidence of type 2 diabetes in the Whitehall II study. Archives of internal medicine.2004;164(17):187380. [DOI:10.1001/archinte.164.17.1873]

31. Keyhani E, Falsafinejad MR, Khodabakhshikoolaee A. Comparison of Marital Satisfaction and Adjustment in Diabetic and Healthy Women. Journal of Diabetes Nursing, 2018, 6(3): 642-652.

32. Hintistan S \& Cilingir D. Sexual dysfunction in Turkish men and women with type 2 diabetes mellitus. Sexuality and Disability.2013; 31(1): 3141. [DOI:10.1007/s11195-012-9271-] 